\title{
Reductive Double Electrophilic Reactions of Methyl Thiophenecarboxylate Mediated by Samarium Diiodide and Hexamethylphosphoramide
}

\author{
Shyh-Ming Yang and Jim-Min Fang* \\ Department of Chemistry, National Taiwan University, Taipei, Taiwan 107, Republic of China
}

\begin{abstract}
The pentadienyl anion generated by treating methyl thiophenecarboxylate with samarium diiodide/ hexamethylphosphoramide in tetrabydrofuran reacts at the C-5 position with a series of benzaldehydes and acetophenones to give the intermediates of samarium dienolates, which are trapped with the second electrophile, such as acetic anhydride, benzyl bromide and carbonyl compounds, in regioselective manners depending on the nature of the electrophile. Thus, the three-component reactions of methyl thiophenecarboxylate with carbonyl compounds are achieved in a one-pot procedure to give 4,5-disubstituted-4,5-dihydrothiophenecarboxylates. (c) 1997 Elsevier Science Ltd. All rights reserved.
\end{abstract}

Aromatic carbonyls usually undergo reductive pinacol couplings on treatment with metals, $\mathrm{SmI}_{2}$ or other low-valent metallic salts. ${ }^{1}$ Our previous studies ${ }^{2}$ showed that the carbonyl-carbonyl coupling reactions are altered to aryl-carbonyl coupling processes by using the combined reagents of $\mathrm{SmI}_{2}$ and HMPA. For example, ${ }^{2 a}$ benzaldehyde is treated with $\mathrm{SmI}_{2}$-HMPA in THF solution to give the dimer, 4-( $\alpha$ hydroxybenzyl)benzaldehyde, after subsequent re-aromatization upon exposure to the air. Acetophenones, ${ }^{2 \mathrm{a}} 2$ cyanoindole-3-carboxaldehydes ${ }^{2 b}$ and thiophenecarboxaldehydes ${ }^{2 c}$ follow the similar processes of arylcarbonyl couplings. This type of reactions is not limited to aromatic carbonyls; we found that thiophene ester 1 was reduced with $\mathrm{SmI}_{2}$-HMPA to generate a pentadienyl anion 2, which underwent consecutive double electrophilic reactions in regio- and stereoselective manners (Scheme 1). This reaction is different from the reported reductive couplings of aromatic esters by samarium-catalyzed electrolysis, giving 1,2-diaryl 1,2diketones. ${ }^{3}$

The typical procedure for the reductive double electrophilic reactions of 1 is described as follows. A dark blue $\mathrm{SmI}_{2}$ solution was prepared by treating $\mathrm{Sm}(4.4 \mathrm{mmol})$ with 1,2 -diiodoethane $(3.7 \mathrm{mmol})$ and HMPA (16 $\mathrm{mmol})$ in THF $(40 \mathrm{~mL})$ at room temperature under an argon atmosphere. The Sml 2 solution was cooled to 0 ${ }^{\circ} \mathrm{C}$, a solution of methyl thiophenecarboxylate $(1.0 \mathrm{mmol})$ and $p$-methoxybenzaldehyde $(1.0 \mathrm{mmol})$ in THF (2 $\mathrm{mL}$ ) was added dropwise. The mixture was stirred at $0^{\circ} \mathrm{C}$ for $10 \mathrm{~min}$ and warmed to room temperature for $1 \mathrm{~h}$. The second electrophile (1.2-1.5 mmol), such as benzyl bromide and ketone, was added. After which the mixture was stirred for $7-10 \mathrm{~h}$ and quenched by saturated $\mathrm{NH}_{4} \mathrm{Cl}$. The mixture was passed through a short silica gel column for removal of HMPA, and the filtrate was chromatographed by elution with gradients of EtOAc/hexane to give the desired products. The results are shown in Table 1 (entries 1-7). Alternatively, the reaction was carried out with two equivalents of a ketone to afford the double hydroxyalkylated products (entries 8-13).

The reactions are considered to be initiated by one-electron transfer from $\mathrm{SmI}_{2}$ to methyl thiophenecarboxylate. The samarium-bound ketyl anion radical did not trap hydrogen atom or undergo acyloin coupling, presumably due to the hindrance of the ligated HMPA molecules. ${ }^{2 a, 4}$ Instead, electron transfer from 


\section{Scheme 1}
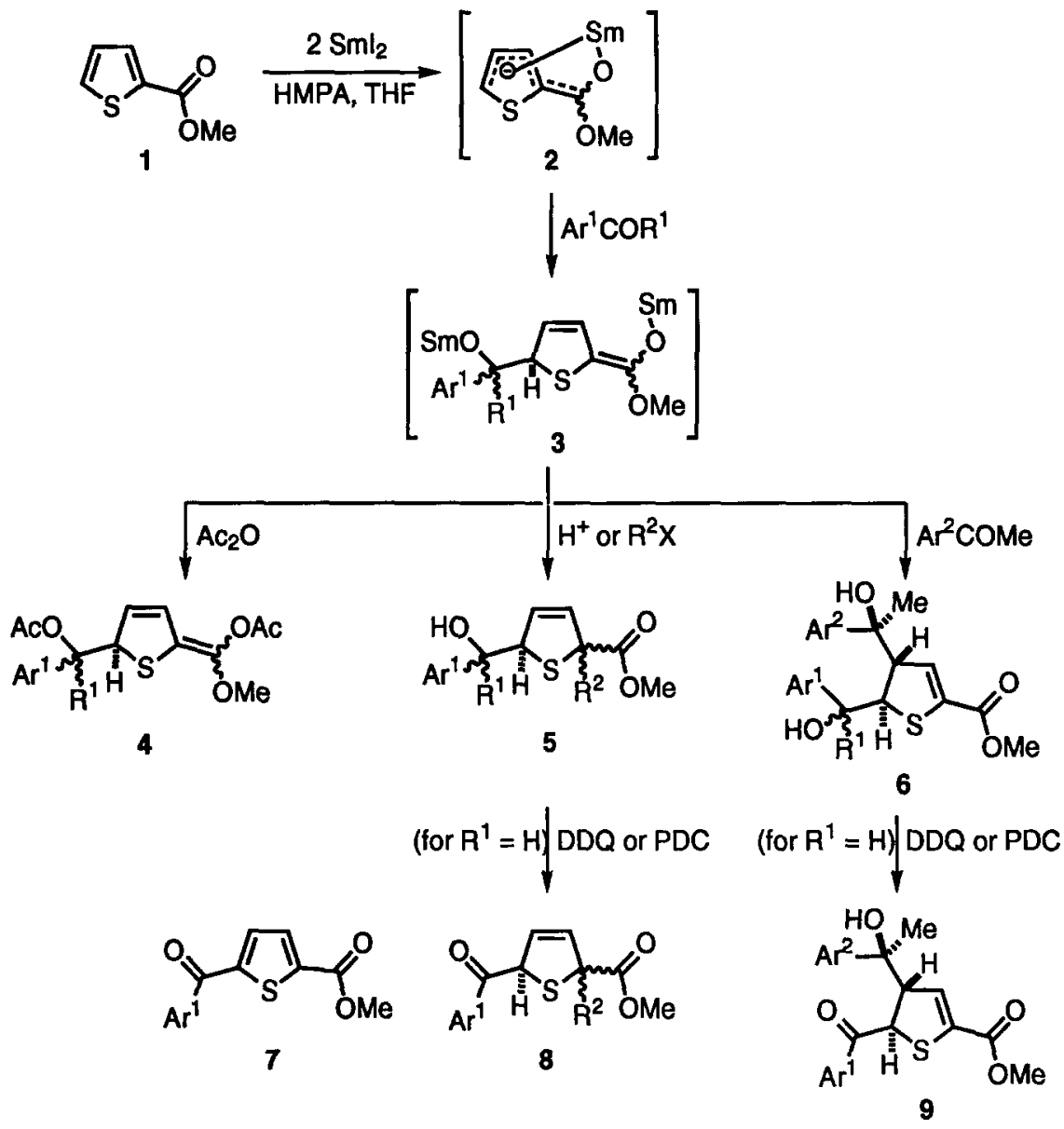

the second molecule of $\mathrm{SmI}_{2}$ would give a pentadienyl anion 2, which reacted with carbonyl compounds selectively at the C-5 position to generate a dienolate 3 consisted of $E / Z$ isomers as shown by the trapping with $\mathrm{Ac}_{2} \mathrm{O}$. The samarium dienolate 3 underwent $\mathrm{O}$-acylation on treating with $\mathrm{Ac}_{2} \mathrm{O}$. Metal dienolates 5 and pentadienyl anions ${ }^{6}$ are versatile reagents in the organic synthesis, though the samarium counterparts are rarely studied. ${ }^{7}$ The protonation and alkylation occurred at the $\alpha$-carbon of 3 , which exerted an additional stabilization by the $\alpha$-sulfanyl group 8 to furnish the observed regiochemistry. The dienolate 3 reacted, however, at the $\gamma$-carbon with ketones, giving the adducts 6 in a stereospecific fashion.

The structures of 4-6 were assigned based on their spectroscopic properties and chemical correlations. The double hydroxyalkylation product $6 \mathrm{f}$, obtained from the reaction with cyclohexanone, was determined to have the trans configuration by an $\mathrm{X}$-ray analysis. The reaction with $p$-methylbenzaldehyde and $p$ chloroacetophenone, as the consecutive electrophiles (entry 5), afforded $6 \mathbf{b}$ as a mixture of two isomers (43:57). The minor isomer was shown by an $\mathrm{X}$-ray diffraction to have the $\left(4 S^{*}, 5 R^{*}, 7 S^{*}, 8 S^{*}\right)$-configuration with the two phenyl groups stacking (dihedral angle $3.15^{\circ}$ ). As both isomers of $6 \mathrm{~b}$ were oxidized with PDC to yield a single benzoyldihydrothiophene $9 \mathrm{~b}$, they must be the epimers differing at the $\mathrm{C}-7$ chirality. The products $6 \mathrm{c}$ and $6 \mathrm{~d}$, existing as epimeric mixtures, were similarly oxidized with DDQ to give 9c and 9d, 
respectively. Compound $6 \mathrm{~g}$, obtained from the reaction of methyl thiophenecarboxylate and acetophenone (2 equiv), consisted of two isomers out of 8 possible diastereomeric pairs. By analogy to the configuration of $6 \mathbf{b}$ $\mathrm{d}$, the two isomers of $6 \mathrm{~g}$ are considered to be the $\mathrm{C}-7$ epimers. This assignment is supported by the NOE study. In the $\left(4 S^{*}, 5 R^{*}, 7 R^{*}, 8 S^{*}\right)$-isomer (major), irradiation of the resonance of Me-7 $(\delta 1.31)$ caused a $15.3 \%$ enhancement of $\mathrm{H}-4$ (at $\delta 3.65$ ), and irradiation of the resonance of Me-8 $(\delta 1.45)$ caused a 12.3\% enhancement of $\mathrm{H}-5(\delta 4.23)$. In the $\left(4 S^{*}, 5 R^{*}, 7 S^{*}, 8 S^{*}\right)$-isomer (minor), irradiation of the resonance of Me-8 ( $\delta 1.16)$ caused a large enhancement $(11.1 \%)$ of $\mathrm{H}-5(\delta 4.03)$, but irradiation of the resonance of Me-7 $(\delta 1.65)$ just caused small enhancements of H-4 (4.3\% at $\delta 3.61)$ and H-5 (4.6\%). Accordingly, the addition of the dienolate 3 to an acetophenone, as the second electrophile (entries 4-7 and 10-13), is proposed to proceed with a chelated transition state $10 \mathrm{a}$, having the phenyl group pointing toward the dihydrothiophene ring to procure a $\pi-\pi$ interaction. The other transition state $10 \mathrm{~b}$ does not operate presumably due to the disfavored steric effect when the methyl group is placed in the dihydrothiophene ring.

Our present study shows a useful method for dearomatization ${ }^{9}$ of methyl thiophenecarboxylate to give disubstituted 4,5-dihydrothiophenecarboxylate by treatment with SmI 2 -HMPA and electrophiles. The first addition of a carbonyl electrophile to the pentadienyl anion 2 is regioselective at $\mathrm{C}-5$, whereas the regiochemistry in the subsequent reaction of the dienolate 3 with a second electrophile is dependent of the nature of the attacking electrophile. The products can be utilized in the synthesis of sulfur-containing polycycles. As thiophene is dearomatized, further removal of the sulfur atom would also be feasible by known procedures. ${ }^{10}$

Table 1. Double electrophilic reactions of the pentadienyl anion generated from methyl thiophenecarboxylate with SmI2-HMPA.

\begin{tabular}{|c|c|c|c|c|c|c|}
\hline entry & first electrophile & second electrophile & $\begin{array}{l}\text { product } \\
\text { (yield } \% \text { ) }\end{array}$ & $\begin{array}{l}\text { ratio of } \\
\text { isomers } \\
\end{array}$ & $\begin{array}{l}\text { oxidizing } \\
\text { agent }\end{array}$ & $\begin{array}{l}\text { product } \\
\text { (yield/\%) }\end{array}$ \\
\hline 1 & $p-\mathrm{MeOC}_{6} \mathrm{H}_{4} \mathrm{CHO}$ & $\mathrm{Ac}_{2} \mathrm{O}$ & $4(43)^{b}$ & $10: 12: 33: 45$ & & \\
\hline 2 & $p-\mathrm{MeOC}_{6} \mathrm{H}_{4} \mathrm{CHO}$ & $\mathrm{NH}_{4} \mathrm{Cl}$ & $5 \mathbf{a}(75)$ & 15:19:30:36 & DDQ & $7(59)^{c}$ \\
\hline 3 & $p-\mathrm{MeOC}_{6} \mathrm{H}_{4} \mathrm{CHO}$ & $\mathrm{PhCH}_{2} \mathrm{Br}$ & $5 \mathbf{b}(64)$ & $8: 14: 25: 53$ & PDC & $8(51)^{d}$ \\
\hline 4 & $p-\mathrm{MeOC}_{6} \mathrm{H}_{4} \mathrm{CHO}$ & $p-\mathrm{ClC}_{6} \mathrm{H}_{4} \mathrm{COMe}$ & 6a $(71)$ & $46: 54$ & & \\
\hline 5 & $p-\mathrm{CH}_{3} \mathrm{C}_{6} \mathrm{H}_{4} \mathrm{CHO}$ & $p-\mathrm{ClC}_{6} \mathrm{H}_{4} \mathrm{COMe}$ & $6 b(63)$ & $43: 57$ & PDC & $9 b(73)$ \\
\hline 6 & $m, p-(\mathrm{MeO})_{2} \mathrm{C}_{6} \mathrm{H}_{3} \mathrm{CHO}$ & $p-\mathrm{MeOC}_{6} \mathrm{H}_{4} \mathrm{COMe}$ & $6 c(77)$ & $45: 55$ & DDQ & $9 c(89)$ \\
\hline 7 & $\begin{array}{l}\text { 1-methylindole-2- } \\
\text { carboxaldehyde }\end{array}$ & $p-\mathrm{MeOC}_{6} \mathrm{H}_{4} \mathrm{COMe}$ & 6d (77) & $35: 65$ & $\mathrm{DDQ}$ & $9 d(88)$ \\
\hline 8 & cyclopentanone & cyclopentanone & $6 e(57)$ & & & \\
\hline 9 & cyclohexanone & cyclohexanone & 6f $(91)$ & & & \\
\hline 10 & $\mathrm{C}_{6} \mathrm{H}_{5} \mathrm{COMe}$ & $\mathrm{C}_{6} \mathrm{H}_{5} \mathrm{COMe}$ & $6 \mathrm{~g}(61)$ & $36: 64$ & & \\
\hline 11 & $p-\mathrm{MeOC}_{6} \mathrm{H}_{4} \mathrm{COMe}$ & $p-\mathrm{MeOC}_{6} \mathrm{H}_{4} \mathrm{COMe}$ & 6h (67) & $47: 53$ & & \\
\hline 12 & $p-\mathrm{CH}_{3} \mathrm{C}_{6} \mathrm{H}_{4} \mathrm{COMe}$ & $p-\mathrm{CH}_{3} \mathrm{C}_{6} \mathrm{H}_{4} \mathrm{COMe}$ & $6 i(60)$ & $48: 52$ & & \\
\hline 13 & $p-\mathrm{ClC}_{6} \mathrm{H}_{4} \mathrm{COMe}$ & $p-\mathrm{ClC}_{6} \mathrm{H}_{4} \mathrm{COMe}$ & $6 j(62)$ & $46: 54$ & & \\
\hline
\end{tabular}

(a) The ratio was determined by the isolated weights of the isomers. Analyses of the ${ }^{1} \mathrm{H}$ NMR spectra of the reaction mixtures showed consistent values. (b) The reaction also gave monoacylated product, 2-(1-acetoxy-1methoxy)methylene-5-( $\alpha$-hydroxy-p-methoxybenzyl)-4,5-dihydrothiophene, in $29 \%$ yield. (c) Oxidation of 5a with PDC in the presence of molecular sieves gave 7 in 55\% yield. (d) Compound 8 was composed of two isomers (33:67). 
<smiles>COC(=O)C1=C[C@H]2[C@@H](O)C(C(=O)OC)=C[C@H](C(C)(O)c3ccc(Cl)cc3)[C@@]2(C)S1</smiles>

$6 b$ (minor)<smiles>COC(=O)C1=CC(C2CCCC2)(C2CCCC2)C(C2(O)CCCC2)C1</smiles>

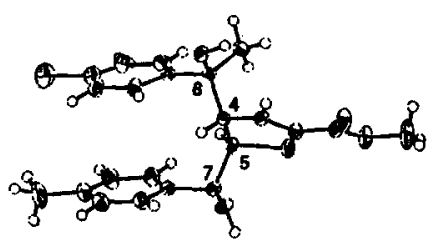

ORTEP drawing of $6 b$ (minor)

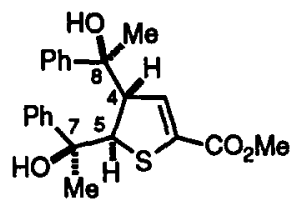

$6 g$ (minor)

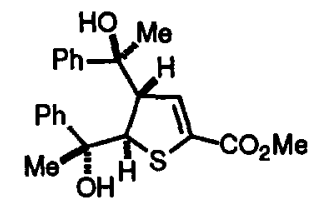

69 (major)

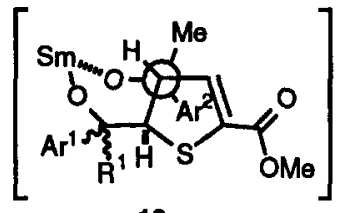

$10 a$

favorable transition state

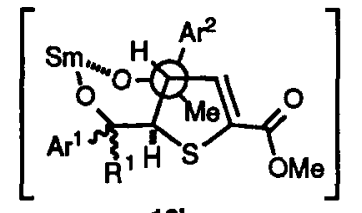

$10 \mathrm{~b}$

unfavorable transition state

\section{References}

1. Kahn, B. E.; Rieke, R. D. Chem. Rev. 1988, 88, 733. (b) Robertson, G. M. in Comprehensive Organic Synthesis, Trost, B. M.; Fleming, I. Eds. Pergamon: Oxford, 1991, Vol. 3, pp 563-611. (c) Wirth, T. Angew. Chem., I nt. Ed. Engl. 1996, 35, 61 .

2. (a) Shiue, J.-S.; Lin, C.-C.; Fang, J.-M. Tetrahedron Lett. 1993, 34, 335. (b) Shiue, J.-S.; Fang, J.M. J. Chem. Soc., Chem. Commun. 1993, 1277. (c) Yang, S.-M.; Fang, J.-M. J. Chem. Soc., Perkin Trans. $11995,2669$.

3. Hébri, H.; Duñach, E.; Heintz, M.; Troupel, M.; Périchon, J. Synlett 1991, 901.

4. Hou, Z.; Yoshimura, T.; Wakatsuki, Y. J. Am. Chem. Soc. 1994, 116, 11169.

5. Caine, D. In Comprehensive Organic Synthesis, Trost, B. M.; Fleming, I. Eds.; Pergamon Press: Oxford, 1991; Vol. 3, pp 1-63.

6. (a) Ernst, R. D. Acc. Chem. Res. 1985, 18, 56. (b) Naruta, Y.; Nishigaichi, Y.; Maruyama, K. J. Org. Chem. 1991, 56, 2011. (c) Yang, C.-C.; Fang, J.-M. J. Chem. Soc., Perkin Trans. 1 1992, 3085.

7. To our knowledge, there is no report on samarium dienolates, though the reactions of samarium enolates are known. (a) Vougioukas, A. E.; Kagan, H. B. Tetrahedron Lett. 1987, 28, 5513. (b) Zang, Y.; Liu, T.; Lin, R. Synth. Commun. 1988, 18, 2003. (c) Curran, D. P. ; Wolin, R. L. Synlett 1991, 317. (d) Molander, G. A.; Etter, J. B.; Harring, L. S.; Thorel, P.-J. J. Am. Chem. Soc. 1991, 113, 8036. (e) Van de Weghe, P.; Collin, J. Tetrahedron Lett. 1993, 34, 3881. (f) Aoyagi, Y.; Yoshimura, M.; Tsuda, M.; Tsuchibuchi, T.; Kawamata, S.; Tateno, H.; Asano, K.; Nakamura, H.; Obokata, M.; Ohta, A.; Kodama, Y. J. Chem. Soc., Perkin Trans 1 1995, 689.

8. Ogura, K. In Comprehensive Organic Synthesis, Trost, B. M.; Fleming, I. Eds.; Pergamon Press: Oxford, 1991; Vol. 1, pp 505-539.

9. (a) Schultz, A. G.; Macielag, M.; Sundaraman, P.; Troveras, A. G.; Welch, M. J. Am. Chem. Soc. 1988, 110, 7828. (b) Bach, T. Angew. Chem, Int. Ed. Engl. 1996, 35, 729.

10. (a) Stotter, P. L.; Hornish, R. E. J. Am. Chem. Soc. 1973, 95, 4444. (b) Nakayama, J.; Yamaoka, S.; Hoshino, M. Tetrahedron Lett. 1988, 29, 1161. (c) Caubére, P.; Coutrot, P. In Comprehensive Organic Synthesis, Trost, B. M.; Fleming, I. Eds.; Pergamon Press: Oxford, 1991; Vol. 8, pp 835-870.

We thank the National Science Council for financial support (Grant NSC84-2113-M002-010) . 